\title{
sciendo
}

Transport and Telecommunication, 2020, volume 21, no. 2, 149-158

Transport and Telecommunication Institute, Lomonosova 1, Riga, LV-1019, Latvia

DOI 10.2478/ttj-2020-0012

\section{MODELLING WHOLESALE COMPANY'S SUPPLY CHAIN USING SYSTEM DYNAMICS}

\author{
Ain Kiisler ${ }^{1}$, Olli-Pekka Hilmola ${ }^{2}$ \\ ${ }^{1}$ Tallinn University of Technology (Taltech), Estonian Maritime Academy, \\ Kopli 101, 11712 Tallinn, Estonia \\ ain.kiisler@taltech.ee \\ ${ }^{2}$ LUT University, Kouvola Unit, Prikaatintie 9 , \\ FIN-45100 Kouvola, Finland; and Tallinn University of Technology (Taltech), \\ Estonian Maritime Academy, Kopli 101, 11712 Tallinn, Estonia \\ olli-pekka.hilmola@lut.fi,olli-pekka.hilmola@taltech.ee
}

\begin{abstract}
Research is based on wholesale and distribution operations of real-life case company, and in this setting, the most critical part of company's supply chain is the inventory replenishment to warehouse (Distribution Center) as well as fulfilling and delivering customers' orders. Different Economic Order Quantity (EOQ)-based models have been considered (Reorder Point, Reorder Point with pipeline on order inventory, and "pulse train"). Simulation system evaluates annual total logistics costs. Results show that in an environment, where local warehouse inventory levels are rather high and replenishment order quantity is rather small, it is important have frequent shipments divided in suitable intervals. In simulation model, this could be done e.g. with the use of "pulse train" function or incorporating pipeline on order inventory in order decision. The research findings are valid for a small-scale supply chain servicing small and geographically limited markets with clients assuming high customer service levels (e.g. 24-hours lead time). For bigger markets, the cross-docking based supply chain models are worth considering in simulations.
\end{abstract}

Keywords: Logistics costs, inventory replenishment models, supply chain simulation, system dynamics

\section{Introduction}

The goal of logistics management should be to reduce the total cost of logistics activities as a whole (Rantasila, 2009), but also trying to assure revenues, value creation and profitability (Hilletofth $e t$ al., 2009; Hilmola et al., 2019). Calculating logistics costs is a complex process even in micro level entities and in the macro context there are only a few attempts to make such assessments (Rantasila, 2013). Logistics activities are very complex and include many different processes. Additional challenges are caused by the difficulties of acquiring transparent information about these processes. Furthermore, calculating the depreciation of all property and equipment involved in logistics activities increases the complexity (Farahani et al., 2009). Together with cost complexity and difficulties of estimation, order lot sizing models has been under pressure, especially within distribution and retail (Zeng et al., 2019) as well as due to low interest rates (and how inventory holding risk should be accounted in the models; Rajabi, 2016; Serrano et al., 2017).

One choice made by companies that has a significant effect on perceived logistics costs is whether the company has decided to outsource its logistics operations or produce these functions internally (Rantasila, 2013). Alongside outsourcing, another essential question for measuring logistics costs is how focally company arranges its inbound and outbound logistics. This defines logistics functions the costs of which are covered by the company. One way to recognize a company's part of the logistics costs is to scrutinize the terms of delivery (Incoterms; Rantasila, 2013).

As for manufacturing enterprises, the total logistics costs comprise several complex dynamic subsystems. And there is a real lag between system variables. Also the factors influencing logistics operational costs can form a causal loop relationship. So the total logistics cost system is a complex and non-linear feedback system, which includes several dynamic subsystems. The system dynamics is a valuable and feasible tool to deal with this system (Chun, 2015).

From a systemic perspective, we can use system dynamics (SD) to study the total logistics costs as a single system (Chun, 2015) or to apply simulation to compare different ordering policies (Torkul et al., 2016). Models may also incorporate maintenance needs and caused delays, in order to examine delivery capability (Sánchez-Ramírez et al., 2020). 
The purpose of this research work is to simulate the supply chain operations of the home appliance wholesale company (named "Distrialpha") for evaluating the annual total logistics costs of this company. Proceeding from this purpose, the system dynamics model was created, using Vensim simulation software. Distrialpha has been teaching case of the authors of this study, and it is compiled from real-life. However, it is old case, and was just used in the following to convert model to system dynamics and learn how to model demanding smoothed delivery flow to distribution center. Cost factors and amounts in the following arise from early 2000.

The rest of paper is organized as follows: Section 2 provides short literature review, and in Section 3 is given the description of simulation object. Section 4 in turn provides discussion of simulation approach and problems, which continues in Section 5 analyzing how simulation model worked out together with simulation results. Final Section 6 provides conclusions and gives some suggestions for further research in this area.

\section{Literature review}

For several decades, system dynamics has been used as a management tool for understanding real world behavior and implementing strategic policies. System dynamics is an approach for exploring the nonlinear dynamic behavior of a system and studying, how the structure and the parameters of the system lead to behavior patterns. Another fundamental purpose of system dynamics is to design effective and robust policies, which enhance performance in managed systems. Undoubtedly, poor policies can give poor performance and potentially unexpected and undesirable behaviors (Lertpattarapong, 2002).

System dynamics methodology provides a comprehensive framework to investigate the dynamic behavior of supply chain as a complex system (Afshar et al., 2014). Therefore, system dynamics model can be used in order to gain more insights into the dynamic nature of supply chain (Bijulal et al., 2011). This helps managers to understand the consequence of each decision making policy. System dynamic models have been widely applied to analyze the system's behavior in order to reduce the system's costs (Sadeghiamirshahidi et al., 2014).

In 1958, the system dynamics was first applied in the field of logistics, where Jay Forrester used to solve the problems that often occurred in industry, such as stock volatility, demand amplification, imbalance between production and labor employment, and the opposite of information technology influence, etc., and published in 1961 the book "Industrial Dynamics". After that, many scholars have applied system dynamics to logistics-related research, such as Nami and Towill (1994), Berry and Naim (1996), Towilll (1996) and Cakravastia and Diawati (1999). They used the dynamic analysis based on negative feedback in system dynamics, combined with the theory and technology of enterprise process reengineering, focusing on the process improvement and design of supply chain.

However, fewer studies exist, which applied system dynamics in costs examinations (Chun, 2015). Typically, simulation studies are operational. In simulation work of Torkul et al. (2016), dynamic reorder point was experienced and its performance was compared to traditional reorder point. Research concluded that higher variation in demand, then the dynamic reorder point typically performs better. SánchezRamírez et al. (2020) used system dynamics to examine delivery system of bottle manufacturing unit, when production line faces maintenance issues. Different scenarios were simulated to assure that delivery capability of end item inventory was sufficient for customers. Maintenance failure was modelled in a way that it could be minor (when manufacturer had spare parts in stock), or major (when item needed to be ordered from supplier with considerable delay involved). Most of the research works in system dynamics are based on classical "beer game" and delayed delivery systems (e.g. Mutallip \& Yasarcan, 2014; Betancur et al., 2014; Rochat et al., 2012). In these research works order quantities are often not fixed, and have enormous variation. Most of the discussion in these studies takes place, how much in order quantity decision we need to take into account current inventory standing, and what is the weight of new customer orders (e.g. Hwarng \& Xie, 2008; Mutallip \& Yasarcan, 2014). As delivery systems are capacity constrained, customers might place numerous orders to assure availability, which in turn could lead to over-investments and over-capacity. These cyclic behaviours can and do happen also in systems, where standardized lot sizes are used. However, as standardized lot sizes are applied, decision maker can not order excessively at once. It has been noted in real-life that automated and standardized purchase order systems are better performing than humans (as latter ones typically over- and underestimate need for product; Rantala \& Hilmola, 2005).

\section{Description of simulation object: supply chain of wholesale company}

The simulation object is a supply chain operated by wholesale company, Distrialpha (fictitious name, and not connected by any means to real case company). Distrialpha is dealing with wholesale and 
distribution of household appliances in Estonia. The company's clients / consignees are local household appliances retail outlets. Distrialpha's main supplier is a Dutch household appliances producer having Distribution Center (DC) near of Rotterdam port, Netherlands, from where purchased orders are shipped. For determining the order size, the Economic Order Quantity (EOQ) method is used. By Distrialpha's logistics management calculation, EOQ is 155 home appliance units or full trailer load (FTL). Parties have agreed in use of Incoterms "EXW supplier's premises" delivery term for their commercial operations. The shipments are delivered to local distribution center in Tallinn, Estonia, using road carrier contracted by Distrialpha. Company has outsourced warehousing services from local warehouse services provider, but is arranging inventory management by its own.

According to Distrialpha's customers' orders, outbound shipments are picked in local DC and shipped to customers. Distrialpha is responsible for arranging deliveries to customers. Distribution transport is outsourced from local service provider. Tables 1 and 2 present the supply chain input parameters data of Distrialpha, being used for creating the system dynamic simulation model.

Table 1. Distrialpha's supply chain operations input data

\begin{tabular}{|c|c|}
\hline \multicolumn{2}{|l|}{ Background data } \\
\hline Goods & Home appliances \\
\hline Average unit EXW purchasing price & 230 euros \\
\hline Average sales margin & $15 \%$, \\
\hline Average unit weight & $50 \mathrm{~kg}$ \\
\hline Average unit volume & $0,45 \mathrm{CBM}$ \\
\hline Minimal sales volume by dealer contract & 1200 units per month \\
\hline Cost of capital & $5 \% /$ year (average long term bank loan interest rate) \\
\hline Average inventory in "Pesukarhu" warehouse & 1200 units (appliances) \\
\hline Inventory turnover & Advisably 12 times \\
\hline Ordering costs & 40 EUR / purchase order \\
\hline
\end{tabular}

By the accounting system of Distrialpha, the total logistics costs of the company consist of the following sub costs:

- Ordering costs,

- International transport costs (inbound transport costs),

- Warehousing costs (goods handling, picking and storage tariffs according to warehouse service provider price list),

- Inventory holding costs (capital cost of stock being in warehouse), and

- Distribution costs (outbound transport costs).

Table 2. Distrialpha's supply chain stages with operational input data

\begin{tabular}{|c|c|}
\hline \multicolumn{2}{|l|}{ SC stage 1 - international/inbound transport } \\
\hline Route & door Rotterdam - door Tallinn \\
\hline Transport provider & Road carrier \\
\hline Vehicle & eurotrailer (90 CBM) \\
\hline Load & FTL, 155 units \\
\hline Tariff & 1800 euros / FTL \\
\hline Time from order receipt to loading & 3 days \\
\hline Transit time & 4 days \\
\hline \multicolumn{2}{|l|}{ SC. stage 2 - warehousing } \\
\hline \multicolumn{2}{|l|}{ Outsourced warehouse } \\
\hline Warehouse service provider price list & $\begin{array}{l}\text { 1. Handling (loading in }+ \text { loading out): } € 0,8 \text { / unit } \\
\text { 2. Picking: } € 2,2 \text { /outbound order } \\
\text { 3. Storage: } € 0.22 \text { /EUR PLL/day } \\
\text { Inventory insurance included in service prices }\end{array}$ \\
\hline \multicolumn{2}{|c|}{ Storage on EUR pallets on APR, in average 2,4 units per 1 EUR PLL } \\
\hline Forecasted average monthly handling volume & $\begin{array}{l}200 \text { outbound orders /month } \\
3 \text { order lines per order } \\
6 \text { units per order }\end{array}$ \\
\hline
\end{tabular}




\begin{tabular}{|l|l|}
\hline SC stage 3 - inventory management \\
\hline EOQ & 155 units (mathematical value rounded to 1 eurotrailer FTL) \\
\hline Inventory capital cost & $5 \%$ of inventory's average value / year \\
\hline SC stage 4 - distribution & $\begin{array}{l}40 \% \text { Tallinn \& surroundings } \\
60 \% \text { other Estonian locations }\end{array}$ \\
\hline Location of clients (by number of inbound orders) & \\
\hline Outsourced distribution & $\begin{array}{l}\text { Overall business practice between wholesalers and retailers is that wholesalers arrange the delivery of all sold /issued from } \\
\text { warehouse goods. }\end{array}$ \\
\hline $\begin{array}{l}\text { Assumed average shipments volume/estimated weights } \\
\text { (proceeding from 1 CBM = 333 kg ratio) and transport tariffs } \\
\text { (by distribution services provider price list including 15\% } \\
\text { volume discounts) }\end{array}$ & \begin{tabular}{l} 
Tallinn \&surroundings: $870 \mathrm{~kg} / € 12.5$ \\
\hline
\end{tabular} \\
\hline
\end{tabular}

\section{Simulation Approach and Problems}

For simulation the Distrialpha's supply chain operations different approaches were considered and tested. The main criterion for assessing the reliability of simulation model was ensuring that Distrialpha is having enough stock in its local DC for fulfilling customers' orders. This means that inventories dispatched and shipped to customers should be replenished on time and in sufficient quantities.

In reality, the Distrialpha warehouse stock replenishment arrangement is based on Distribution Requirements Planning (DRP) system. The reorder point (ROP) is 1200 units (due to product variety, however, in this simulation model, only one washing machine model is assumed to be used). When the stock drops to 1200 units or below, the replenishment order in amount of EOQ (155 units; one trailer in Full Trailer Load) is placed to supplier. The ROP is based in reality on inventory position (on hand inventory - customers' orders + on order inventory), not on in hand inventory. As the average interval between replenishment orders is around 3.5 days and supplier's order cycle time is seven days, and the next replenishment order should be placed before the moment, when supplier's shipment according to previous order has been received to Distrialpha's local DC. This means, that there are permanently several shipments of transit inventories in supply chain, describing of which in simulation model is extremely complicated.

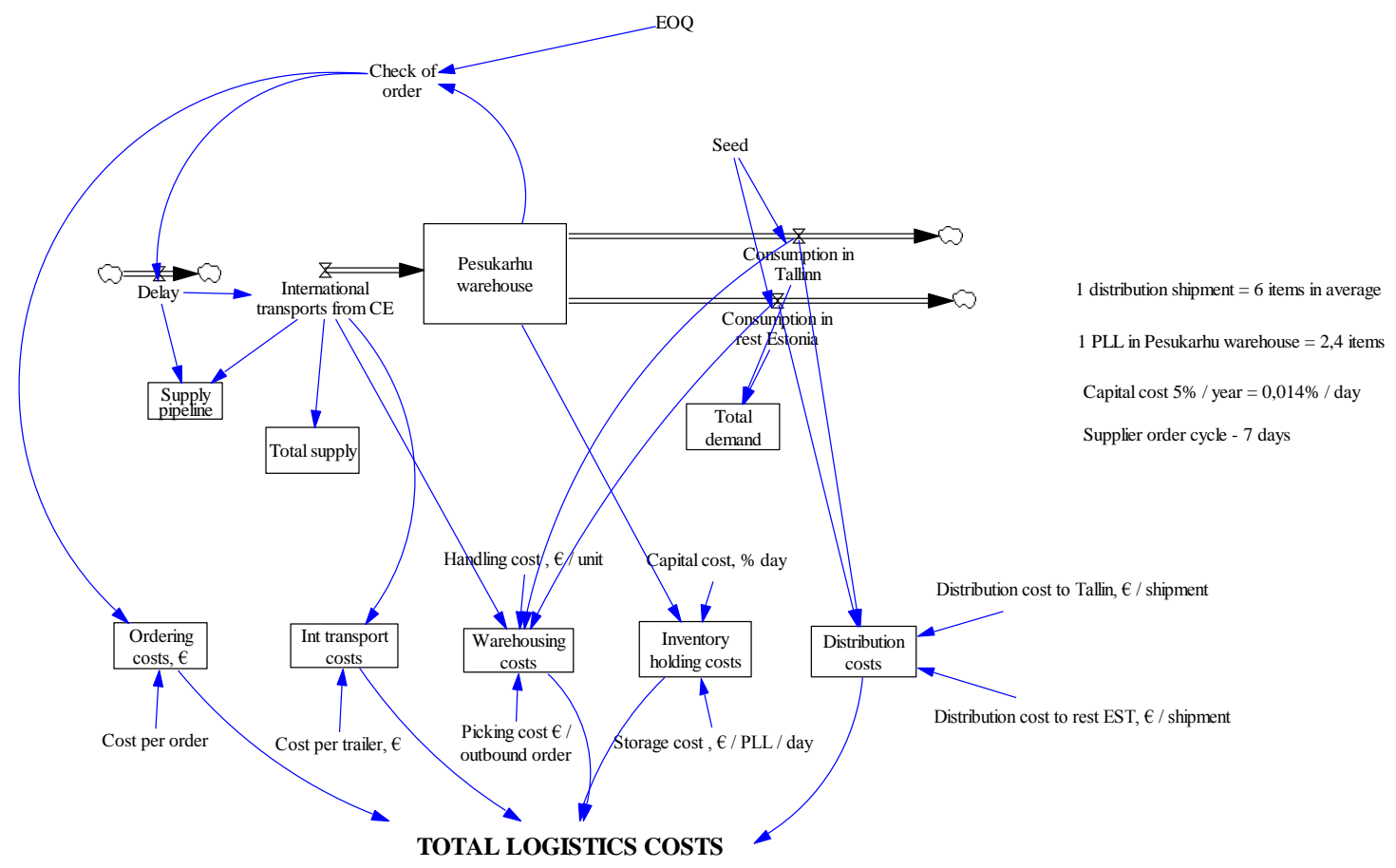

Figure 1. Initial Distrialpha's supply chain operation simulation model based on ROP replenishment approach 
The above mentioned existence of several simultaneous transit shipments in pipeline also excludes the possibility of using simple Economic Order Quantity (EOQ), and its Re-Order Point (ROP) replenishment method in simulation (at the same time taking into account delivery delays). EOQ model presumes that the preceding replenishment order should be received, before the next replenishment order can be placed. The attempt to use EOQ with ROP in simulation model was made (Figure 1), but simulation showed that in that case placement and receipt of replenishment orders is going in "batches" separated from each other long-term intervals. For example, by simulation, starting from second day there were nine succeeding days, when replenishment orders are placed on each day, then 27 days followed without any ordering. Then again were 11 ordering days (each day one order) followed by 25 order free days, etc. The ordered quantities / shipments arrived in same manner, only with 7 days delay (Figure 2; seven days is supplier order cycle / delivery time, submitted into simulation). From the perspective of inventory management, this means too high and strongly fluctuating stock level (Figure 2) accompanying too high inventory carrying costs (and fluctuating inventory space need together with labour).

We also built model from EOQ/ROP, which takes into account "on order inventory" or "supply pipeline" (like named in simulation model), and then we made feed forward linkage from delivery process to order decision (that inventory considered includes also delivery pipeline). This resulted on desirable effects, where orders were not any more batched together, but they were spread around rather evenly (Figure 3). This also resulted on much lower average inventory levels, and smaller fluctuation of inventories (Figure 3). Simulation, however, is not resembling reality in that good fashion as inventory levels are all the time below 1200 units. This small change thus illustrates in good fashion, how important it is to have "supply pipeline" taken into account within order decisions as well as simulation modelling (being one-step closer to DRP).

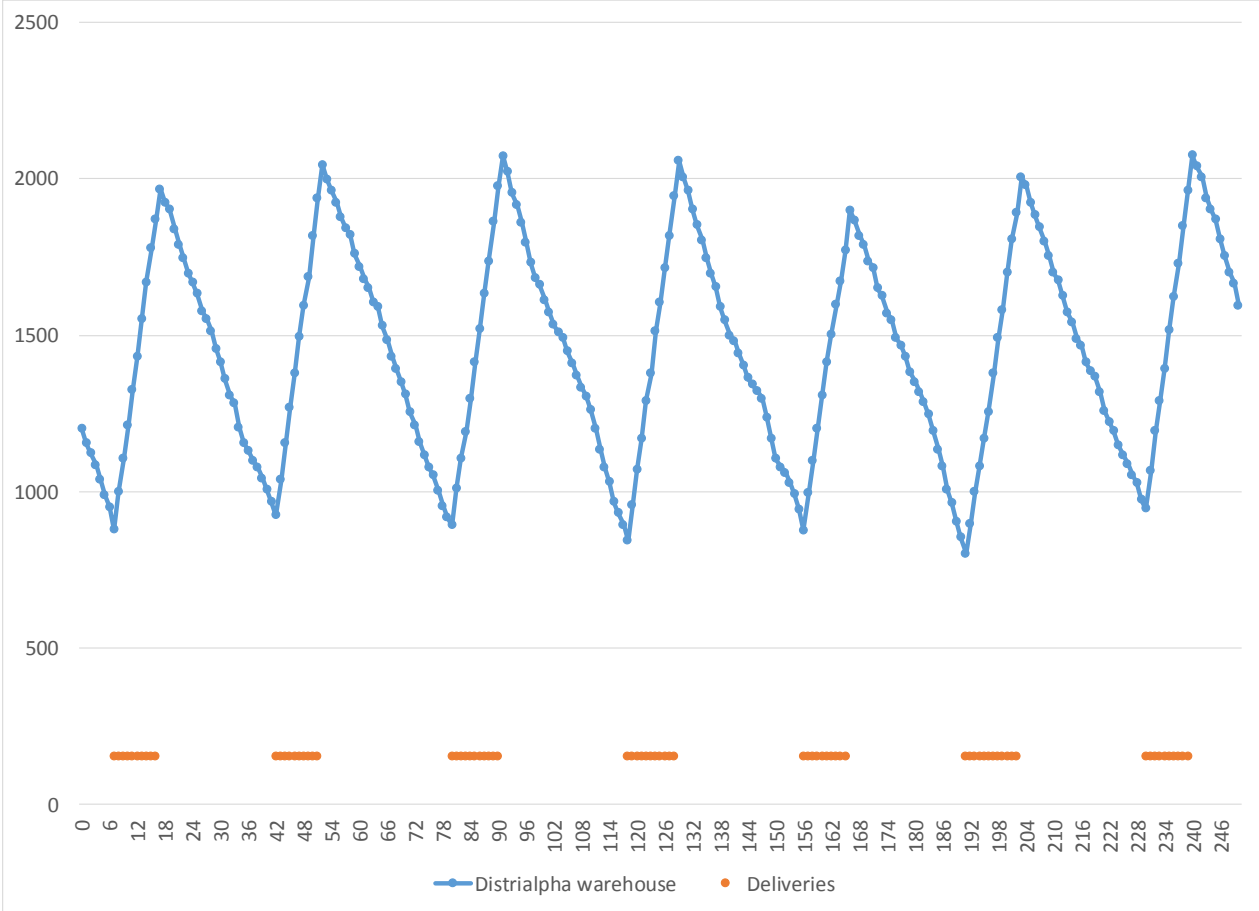

Figure 2. Distrialpha's stock levels using EOQ/ROP inventory replenishment model (Distrialpha warehouse) and international shipments arriving in "batches" into warehouse (Deliveries)

Finally, the pulse train function was found to be most feasible for simulating given supply chain operations (from simulation program Vensim). Pulse train is producing repetitive series of action, like pulses (in this case order of FTL truck from Rotterdam to Estonia), and these pulses are happening in same fixed time intervals. In the case of given supply chain simulation, pulse train describes the inbound flows to Distrialpha's local DC, arriving in constant quantities in constant intervals. Use of pulse train function involves the removal of EOQ/ROP check function from simulation. This can be accepted as by input parameters demand and amount of good flows are both stable, and without remarkable fluctuations. This sort of function has been used in lot sizing related studies (of manufacturing) e.g. to model maintenance failures (Ramírez et al., 2020). 


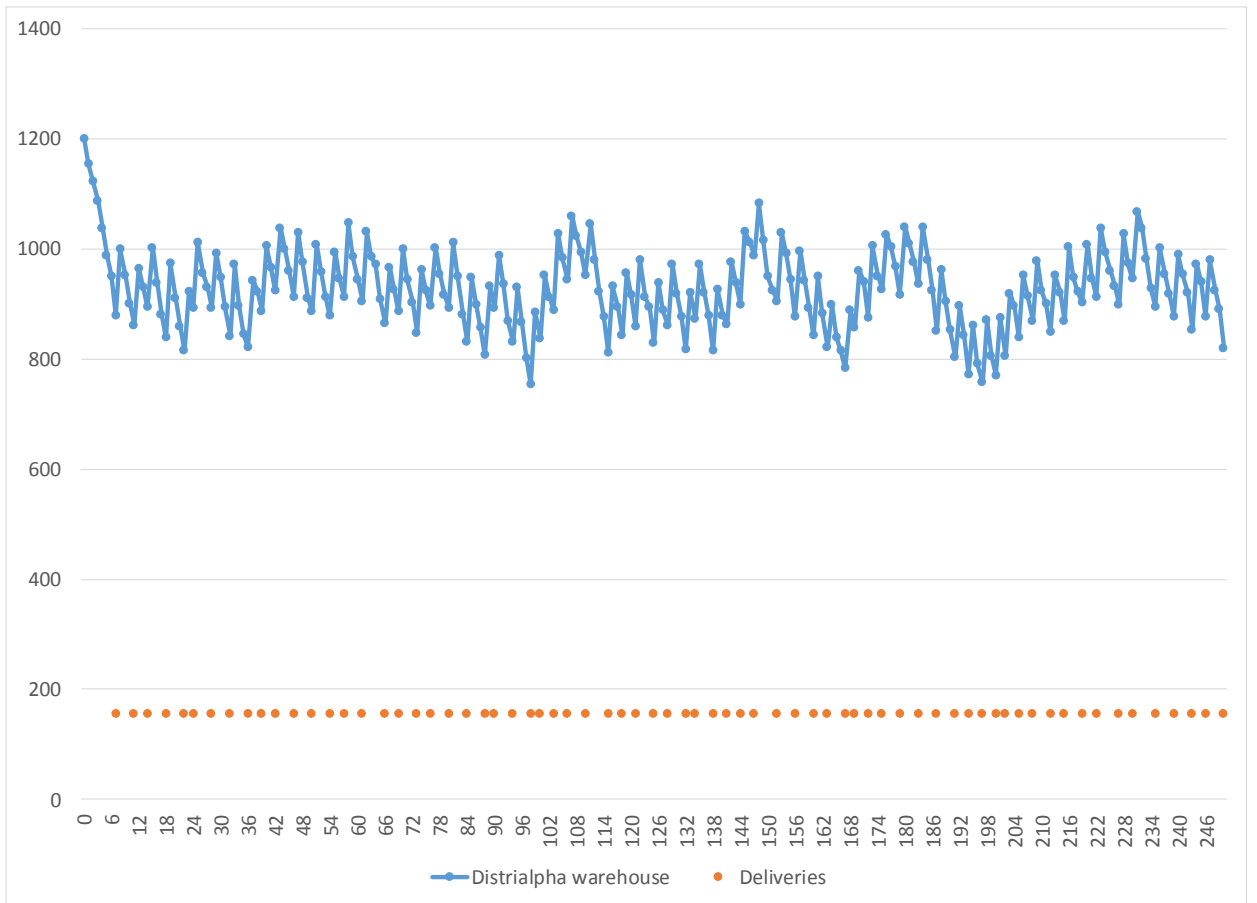

Figure 3. Distrialpha's stock levels using EOQ/ROP inventory replenishment model as taking supply pipeline into account (Distrialpha warehouse), and international shipments arriving in smoother flow into warehouse (Deliveries)

\section{Closer to Reality with Pulse Train Function}

Figure 4 presents the final simulation model. Customers' demand activates the outbound goods flows from Distrialpha's warehouse in the form of picked, loaded and shipped outbound orders. There are two outbound flows - to clients situated in Tallinn and its surroundings (Harjumaa) and to clients situated in the rest of locations in Estonia. The day to day demand simulation is modelled on the base of uniform distribution in predetermined max and min limits.

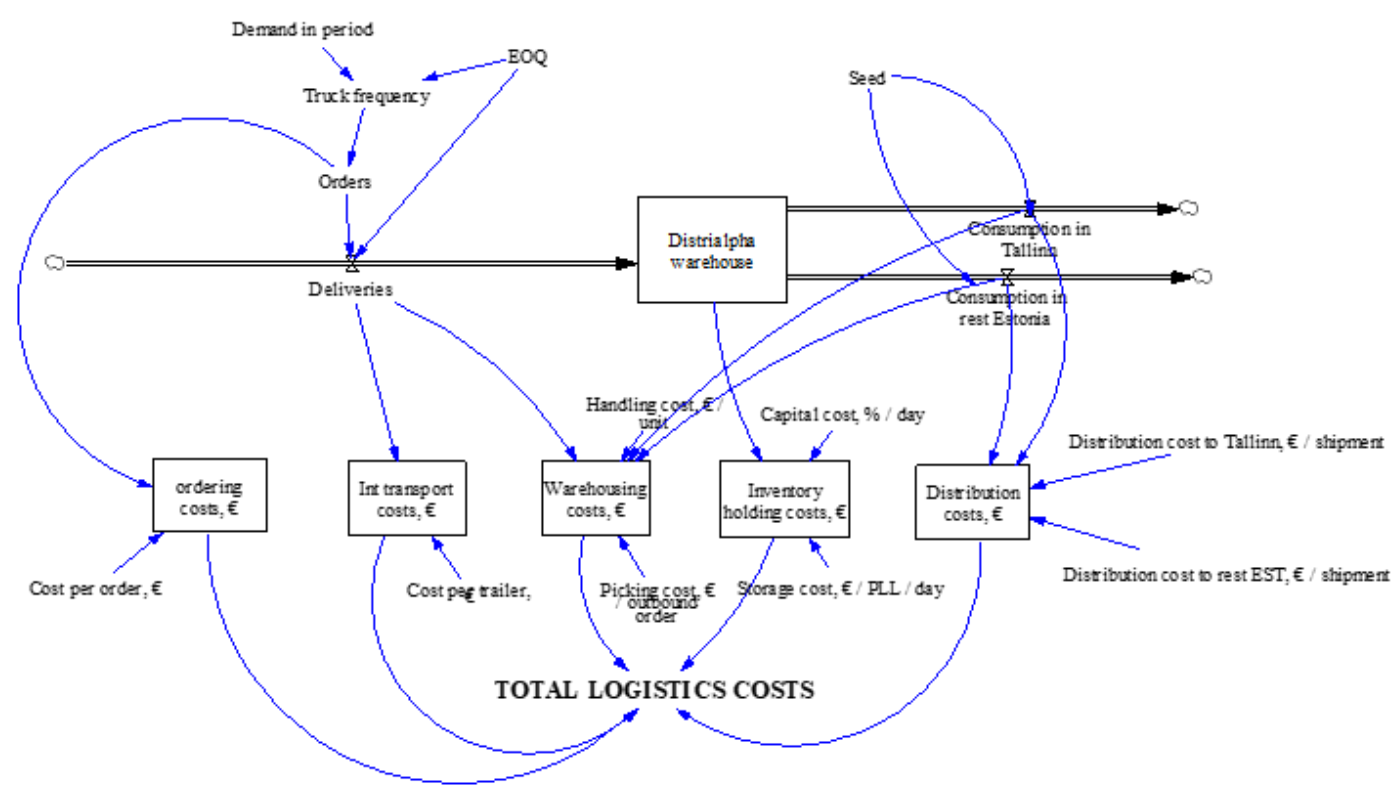

Figure 4. Distrialpha's supply chain operation simulation model basing on "pulse train" replenishment approach 
Lyneis argues that by using system dynamics models can be produced more reliable forecasts than by using statistic models (Lyneis, 2000). Forecasting demand is a key tool in managing uncertainty. Forecast accuracy depends on the understanding and coverage of parameters as well as the accuracy of historic data available for each variable that may have an impact on the forecast or predictive analytics (Datta et al., 2009).

The inbound flow has no direct relationship to day-to-day outbound flows. However, the frequency of incoming trailers has been determined on the basis of total yearly demand (250 working days). The total yearly demand was found, letting simulation to "forecast" the 250 days total demand on the base of uniform distribution, and rounding this forecast to a little bit lower total amount $(11,000$ units per year) as random demand has always variance, and there was considerable amount of inventory in the warehouse available. Proceeding from this yearly demand ("Demand in a period") and predetermined EOQ ("EOQ"), simulation finds (constant) frequency of deliveries, which are received to warehouse as pulse train (see Figure 4).

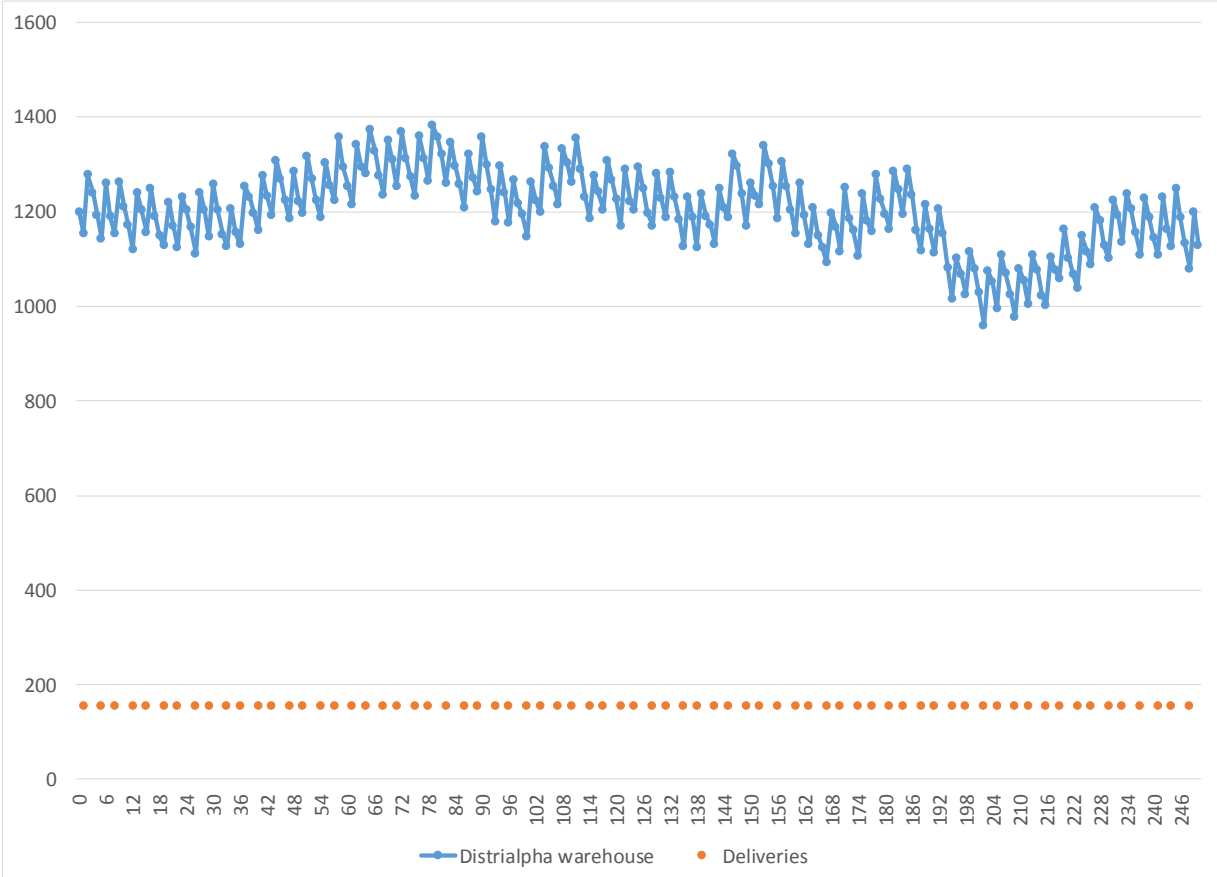

Figure 5. Distrialpha's stock levels dynamics using "pulse train" inventory replenishment model (Distrialpha warehouse) and corresponding inventory replenishments (Deliveries)

So, the stock in Distrialpha's warehouse is replenished in constant rate (constant quantities, constant intervals), but outbound flow varies depending on customers demand, resulting in variation of stock level (see Figure 5). In comparison with ROP based simulation model described in the previous part firstly, pulse train inventory replenishment model allows to achieve higher frequency inventory replenishment rates resulting in more stable and optimal inventory level (Figure 5). It is similar in performance as taking in ROP pipeline inventory into account, however, it is predictable in shipment days.

Table 3 summarizes performance of three different order systems as it is used 10 different seed values to generate final demand (in earlier figures developments were based on one seed run). On average both ROP with pipeline demand account as well as pulse train model have much lower average and median performance as compared to ROP model. In both, average and median terms, ROP with pipeline model is resulting around $36 \%$ lower inventory holdings, as situation with Pulse Train is $20.3 \%$ lower in average and $18.4 \%$ lower in median terms. Other measures follow this - min, max and st. dev. are highest in ROP. This means that there is variation in system, and peak demand for warehouse space is rather high.

Table 3. Distrialpha's supply chain stages with operational input data

\begin{tabular}{|l|r|r|r|r|r|}
\multicolumn{1}{r}{ Average } & \multicolumn{1}{c}{ Median } & \multicolumn{1}{c}{ Min } & \multicolumn{2}{c}{ Max } & \multicolumn{1}{c}{ St. Dev. } \\
\hline \hline ROP & 1446.8 & 1447.0 & 776.0 & 2154.0 & 340.0 \\
\hline ROP with pipeline & 925.3 & 923.0 & 753.0 & 1200.0 & 65.8 \\
\hline Pulse Train & 1153.1 & 1181.0 & 486.0 & 1488.0 & 165.8 \\
\hline
\end{tabular}


On the basis of unit flows quantities and logistics costs \& tariffs charged by logistics services providers, the logistics costs for operating the supply chain are calculated and summed up as total logistics costs.

The annual (250 working days period) total logistics costs for the looked simulation rounds with 10 different seed values of demand are 224162.4 euros for pulse train model (lowest cost was of course "ROP with pipeline", on the aver. in total 217243.6 euros). Ordering and international transport costs are constant by simulation rounds, while the rest of logistics costs can somewhat vary depending on rounds (variation in outbound flows according to uniform distribution of demand).

Major logistics costs component is international transport, making $57.01 \%$ of total logistics costs (in pulse train model). Together with distribution costs, the share of transportation costs is already $78 \%$ (distribution costs separately, 21\%). The share of inventory carrying cost is $11.8 \%$, warehousing costs $8.9 \%$ and ordering costs $1.3 \%$.

Actually warehousing costs should be somewhat higher than from simulation due to additional storage costs for days not covered by simulation model. LSP providing warehousing services charges Distrialpha for cargo handling, picking and storage (Table 2). Concerning storage, simulation is created for 250-days period (business days in a year). However, storage charges should apply for all 365 yeardays, including holiday period.

\section{Conclusions}

For the wholesale company's supply chain model simulation disserted, the most critical part of modelling supply chain is inventory replenishment in local DC fulfilling and dispatching customers' orders. For simulation of given replenishment operations different EOQ-based approaches (DRP, ROP, and pulse train) were considered and tested. Simulation results show that from mentioned replenishment models the pulse train model is best applied for given supply chain simulation.

The simulation findings are valid for a small-scale supply chain servicing small and geographically compact markets with clients requesting high customer service (as given supply chain focusing on Estonian market). For bigger markets, also the cross-docking based supply chain models are worth considering. Product variety also creates challenges, and system dynamics is not capable of handling numerous products simultaneously.

However, proceeding from disserted supply chain simulation input parameters (Tables 1-2) and total logistics costs calculated in simulation, using cross-docking is not reasonable. The number of shipments dispatched from Distrialpha's DC is limited (ca 200 shipments per month), clients wish 24-hours delivery time and the transport costs (inbound+outbound) form already ca $3 / 4$ of total logistics costs. Current inventory and warehousing costs are relatively low. Implementing of cross-docking system in given case will increase several times the frequency of inbound deliveries resulting in higher transport costs and total logistics costs thereof.

This research as well as our earlier experiences from distribution and retail are such that product variety, uncertainty at markets as well as possibility of using cross-docking practices create limitations on simulation models. We would like to continue enlarging models using simulation methodology of this study, and in cost examination would like to have included transportation fleet need (how many at max. are needed, investments) as well as warehousing space and labour demand (it is different, if demand varies a lot due to using large lot sizes). This variation of demand and its implications of course depend from environment - are warehouse operations outsourced or not, and does warehouse have any other customers to serve. Larger once used lot sizes (or "batch" of orders) must have cost implications, and then variables are different for smoother product flow.

\section{References}

1. Afshar, J., Sadeghiamirshahidi, N., Firouzi, A.R., Shariatmadari, S. \& Hassan, S. (2014). System dynamics analysis of a blood supply chain system. Applied Mechanics and Materials, 510, pp. 150-155.

2. Betancur, S. V., Castaño, G. U. \& Gonçalves, P. (2014). Exploring duplicate orders in a single-manufacturer multi-distributor supply chain. Proceedings of System Dynamics Conference (Delft). Available at URL: https://proceedings.systemdynamics.org/2014/proceed/papers/P1437.pdf Retrieved: Jan.2020.

3. Berry, D. \& Naim, M. M. (1996). Quantifying the Relative Improvements of Redesign Strategies in A P.C. Supply Chain. International Journal of Production Economics, 46, pp. 181-196. 
4. Bijulal, D., Venkateswaran, J. \& Hemachandra, N. (2011). Service Levels, System Cost and Stability of Production-inventory Control Systems. International Journal of Production Research, 49(23), pp. 7085-7105.

5. Cakravastia, A. \& Diawati, L. (1999) Development of System Dynamic Model to Diagnose the Logistic Chain Performance of Shipbuilding Industry In Indonesia. International System Dynamics Conference Proceedings, Wellington. Available at URL: http://proceedings.systemdynamics.org/1999/PAPERS/PARA74.PDF Retrieved: Nov.2019

6. Chun, F. (2015). The Simulation and Optimization Research on Manufacturing Enterprise's Supply Chain Process from the Perspective of Social Network. Journal of Industrial Engineering and Management, 8(3), pp. 963-980.

7. Datta, S., Granger, C., Graham, S., Sagar, N., Doody, P., Slone, R. \& Hilmola, O-P. (2009). Forecasting and Risk Analysis in Supply Chain Management: GARCH Proof of Concept. MIT ESD Working Paper Series GARCH PROOF OF CONCEPT: Forecasting and Risk Analysis in Supply Chain Management. Available at URL: https://dspace.mit.edu/handle/1721.1/102861 \& https://dspace.mit.edu/bitstream/handle/1721.1/43948/garchproofofconcept_datta_granger_graham_s agar_doody_slone_hilmola_18december2008_final.pdf?sequence=1. Retrieved: Nov.2019.

8. Farahani, R. Z., Asgari N. \& Davarzani, H. (2009). Supply Chain and logistics in National, International and Governmental Environment - Concepts and Models. Physica-Verlag Heidelberg: Berlin, Germany.

9. Hilletofth, P., Ericsson, D. \& Christopher, M. (2009). Demand chain management: a Swedish industrial case study. Industrial Management \& Data Systems, 109:9, pp. 1179-1196.

10. Hilmola, O-P., Andres, T. \& Panova, Y. (2019). Global corporations and smaller actors in textile business: European perspective. Economy of Region, Centre for Economic Security, Institute of Economics of Ural Branch of Russian Academy of Sciences, 1:1, pp. 216-230, doi 10.17059/2019-117, http://economyofregion.ru/Data/Issues/ER2019/March_2019/ERMarch2019_216_230.pdf

11. Hwarng, H. B. \& Xie, N. (2008). Understanding supply chain dynamics: A chaos perspective. European Journal of Operational Research, 184, pp. 1163-1178.

12. Lertpattarapong, C. (2002). Applying System Dynamics Approach to the Supply Chain Management Problem. MIT master thesis. Available at: https://core.ac.uk/download/pdf/4395696.pdf Retrieved: Nov.2019.

13. Lyneis, J. M. (2000). System dynamics for market forecasting and structural analysis. System Dynamics Review, 16:1, pp. 3-25.

14. Mutallip, A. and Yasarcan, H. (2014). Effect of lead time on anchor-and-adjust ordering policy in continuous time stock control systems. Proceedings of System Dynamics Conference (Delft). Available at URL: https://proceedings.systemdynamics.org/2014/proceed/papers/P1061.pdf. Retrieved: Jan. 2020

15. Nami, M. M. \& Towill, D. R. (1994). Establishing A Framework for Effective Materials Logistics Management. International Journal of Logistics Management, 1, pp. 81-88.

16. Rantasila, K. (2013). Measuring Logistics Costs - Designing a generic model for assessing macro logistics costs in a global context with empirical evidence from the manufacturing and trading industries. Publications of Turku School of Economics, Series A-8:2013.

17. Rantala, L. \& Hilmola, O-P. (2005). From manual to automated purchasing, case: middle-sized telecom electronics manufacturing unit. Industrial Management and Data Systems, 105:8, pp. 10531069.

18. Rajabi, A. M. (2016). A revision on cost elements of the EOQ model. Studies in Business and Economics, 11:1, pp. 5-14.

19. Rochat, L. \& Acker, A. V. (2012). The impact of competitive interactions on category penetration and purchase frequency of mature FMCG categories. Proceedings of System Dynamics Conference (St. Gallen). Available at URL: https://proceedings.systemdynamics.org/2012/proceed/papers/P1123.pdf Retrieved: Jan.2020

20. Sadeghiamirshahidi, N., Afshar, J., Firouzi, A. \& R. Hassan, S. (2014). Improving the Efficiency of Manufacturing Supply Chain Using System Dynamic Simulation. Jurnal Teknologi, 69:2, pp. 123-125.

21. Sánchez-Ramírez, C., Ramos-Hernández, R., Fong, J. R. M., Alor-Hernández, G. \& García-Alcaraz, J. L. (2020). A system dynamics model to evaluate the impact of production process disruption on order shipping. Applied Sciences, 10:1, 208. 
22. Serrano, A., Oliva, R., and Kraiselburd, S. (2017). On the cost of capital in inventory models with deterministic demand. International Journal of Production Economics, 183, pp. 14-20.

23. Towill, D. R. (1996). Industrial Dynamics Modeling of Supply Chains. International Journal of Physical Distribution \& Logistics Management, 2, pp. 23-42.

24. Torkul, O., Yilmaz, R., Selvi, I. H. \& Cesur, M. R. (2016). A real-time inventory model to manage variance of demand for decreasing inventory holding cost. Computers \& Industrial Engineering, 102, pp. 435-439.

25. Zeng, S., Nestorenko, O., Nestorenko, T., Morkunas, M., Volkov, A., Belezentis, T. \& Zhang, C. (2019). EOQ for perishable goods: Modification of Wilson's model for food retailers. Technological and Economic Development of Economy, 25:6, pp. 1413-1432. 